\title{
Impact of Merger and Acquisition Practice on Job Stress: Evidence from Nepal
}

\author{
Dr. Prakash Shrestha ${ }^{1} \quad$ Dr. Dilip Parajuli ${ }^{2 *}$ \\ 1. Lecturer, Nepal Commerce Campus, Faculty of Management, Tribhuvan University, Nepal \\ 2. Associate Professor, Bhaktapur Multiple Campus, Faculty of Management, Tribhuvan University, Nepal
}

\begin{abstract}
M\&A has become one of the key aspects of corporate change and transition. It has also become a source of uncertainly and stress for everyone. Nepal Rastra Bank has extensively introduced the policy of M\&A in the banking and financial sector of Nepal. The main aim of this study is to examine the impact of M\&A practices on job stress of employees and to suggest some policies to manage such job stress. This uses both descriptive and analytical approaches to research. A set of a self-administered questionnaire used to explore the impact of M\&A practice on the job stress of employees. A total of 500 questionnaires (125 in each merged bank) were distributed to all level managers, branch managers, and other staff of various departments of the commercial banks involved in big M\&A practice in Nepal. Only $351(70.20 \%)$ of total distributed questionnaires were returned as a source of data. A five-point Likert scale is used for measuring responses. This study uses analytical statistical tools such as mean, standard deviation, regression analysis, and ANOVA test for analyzing data. The results indicate that individual-related problems, policies \& procedure-related problems, job-related problems, and organizationrelated problems are the key stressors in M\&A practice. The results also reveal that all these problems have a significantly positive impact on employee job stress after M\&A practice. This study also suggests several policies for managing and reducing the job stress of employees after M\&A practices.
\end{abstract}

Keywords: Acquisition, Employees, Job, Merger, Stress

DOI: $10.7176 / \mathrm{EJBM} / 12-24-01$

Publication date:August $31^{\text {st }} 2020$

\section{Introduction}

A transitional phase, whether it can be in politics, economics, and organizational life, is always a source of tension and stress for everyone. Whatever change occurs in organizational life, it definitely affects the position and income of employees. So, it is believed that the change in organizational activities and practices have a direct effect on employee status and their psychological aspects. In recent times, merger and acquisition (M\&A) have become one of the key aspects of organizational transition. The practice of M\&A has created change in organizational life. So, M\&A has become worth discussing and research areas for companies as their strategic option (Basnet \& Acharya, 2018) for making change and preparing for intense competition in the market. Matteson and Ivanceich (2008) argue that M\&A activity can create stress for all employees, particularly those at mid-career.

M\&A practice has extensively introduced in the banking sector of Nepal. Mostly in a rapidly changing business environment, the banking sector is facing unprecedented turmoil in the market (Goyal \& Joshi, 2014). Intense competition, advancement in modern technology, recession in the global economy, volatility in the stock market, and increasing interest rates have created a huge trouble for bankers to deliver superior performance and to sustain their business. In such a case, merging two or more companies into one company is one of the prominent strategies used by the companies to increase market shares, reduce costs, and create synergy (Thompson \& Martin, 2005; David, 2011; Hubbard, Rice, \& Galving, 2015; Rao, 2016; Wheelen, Hunger, Hoffman, \& Bamford, 2018). Bartels, Douwes, Jong, and Pruyan (2006) also acknowledged that M\&A may involve a difficult process with uncertain outcomes. Cartwright and Cooper (2014) also argued that many problems seem to refer to one underlying incident that in M\&A processes employees of the new company may feel vulnerable when their group is endangered by the 'infusion' of new identities and that they are still supposed to grip with the group they are already apart. As a result, employees may lose the psychological bond between groups and this creates employees' job stress (Basnet \& Acharya, 2018).

Nepal Rastra Bank (NRB), the central bank of Nepal, has directed banks and financial institutions (BFIs) to go in the process of M\&A providing several benefits. Responding to such benefits presented by NRB, many BFIs are opting in the process of M\&A in Nepal (NRB, 2015). In recent years, M\&A has become a burning issue in our banking sector. Complying with the global scenario, our banks, and financial institutions are currently going through the practices of M\&A.

In addition, many BFIs practice M\&A as a strategic choice which has broadened the value of research in this field. So, studying the effects of M\&A on employee job stress is significant. In recent days, intangible factors such as aspects of human resources, culture, information, etc., along with other tangible assets, such as capital, raw materials, and equipment, play a vital role in the success or failure of companies. During the M\&A process, 
companies mainly focus on cost-cutting strategies, due to that the employees might fear the loss of their jobs (Panthi, 2012). This will cause de-motivation and discouragement among them. M\&As are particularly stressful mostly because the employees have not developed an effective set of coping strategies to deal with such a novel and emotive situation that affects a wide range of work issues (Schweiger \& Ivancevich, 1987). It is often these uncertainties, rather than the actual changes themselves that are more stressful to employees (Moran \& Panasian, 2005). Buone and Bowditch (1989) also mentioned that during the M\&A process, spreading rumor, and the grapevine work overtime leads to more anxiety and, in many cases, counterproductive behaviors. Often based on fears rather than reality, these rumors can significantly intensify employee anxiety, tension, and stress. Whittle (2002) also argued that organizational change associated with M\&A has an impact on the stress of employees and their families.

\section{Literature Review}

M\&A is weighted down with the practice of terms such as merger, acquisition, takeover, and amalgamation in literature. Many researchers (Machiraju, 2003; Adeyinka, Emanuel, \& Daniel, 2015; Roberts, Wallace, \& Moles, 2010; Dhungana, 2013) use these terms synonymously. So far the impact of M\&A on job stress is concerned; Seo $\&$ Hill (2005) identified six theoretical themes such as anxiety theory, social identity theory, acculturation theory, role conflict theory, job characteristics theory, and organizational justice theory. These theories have implicitly or explicitly formed the basis for explaining employees' psychological and behavioral responses to M\&A-related organizational change.

Job stress is an unsatisfactory product of M\&A practice. It is due to the negligence and mismanagement of human resources. Some stressful activities of management also create job stress after M\&A practice has taken place. Job stress is the condition of feeling ill at workplaces to anxiety leading to depression. In organizational life, major organizational change and restructuring result in increased stress, confusion, and lost productivity. It takes a long time to regain satisfaction (Gibbons, 1998). In a study, Geber (1987) reported that there is a worrying factor that results in an immediate drop-off in productivity after M\&A practice because workers feel their security is threatened and therefore are too distracted to do their jobs properly. A study of Sajeewani (2012) argued that a merger is a form of an organizational restructuring that leads to higher workload, changes in duties, and responsibilities, and an increase in role ambiguity, work overload, and role conflict. This also argued that mergers between different cultures lead to a decrease in employee efficiency and a rise in job stress because it is apparent that some types of culture promote the process of transition while other types of culture do not. Cartwright (2005) also mentioned that some of the unpredicted and irregular strategic options of organizations like M\&A; events are considered to set employees' experience apart from other forms of organizational change and so further increase their stressful potential.

Habeck, Kroger, and Trâm (2000) found five situations where people feel stress. They include (a) loss of status and former sphere of influence; (b) lack of transparency about the company's intentions; (c) fierce fight for survival; (d) increased workloads because some people leave, either voluntarily or involuntarily; (e) the spillover effect on personal lives. Kahn et al. (1964) argued that in the M\&A process, whenever an individual does not agree with his/her assessment or accepts roles that are beyond an individual's capacity leads to role stress in terms of ambiguous or overloading or conflicting. They further added that role ambiguity takes place where there is a lack of necessary information for an organizational position, resulting in role dissatisfaction, anxiety, fear and hostility, and lower performance leading to role conflict that creates inconsistent behavioral expectations. Ashford, Lee, and Bobko (1989) also identified that the employees perceive greater job insecurity with a greater number of changes in their organization. Employees of the acquired firm, finding themselves 'sold' as a commodity, may suffer from feelings of worthlessness and may feel inferior because of loss of autonomy and status (cited in Moran \& Panasian, 2005). The following table shows the empirical studies regarding the impact of M\&A on job stress. 
Table 1. Different Views on M\&A Practices and Job Stress

\begin{tabular}{|l|l|}
\hline \multicolumn{1}{|c|}{ Author(s)/Date } & \multicolumn{1}{c|}{ Main views } \\
\hline Geber (1987) & $\begin{array}{l}\text { M\&A creates job stress because it threatens workers' security and distracts them } \\
\text { from their jobs. }\end{array}$ \\
\hline $\begin{array}{l}\text { Ashford, Lee, and Bobko } \\
\text { (1989); Moran and } \\
\text { Panasian, 2005) }\end{array}$ & $\begin{array}{l}\text { M\&A creates job stress because the employees of the acquired firm lose their } \\
\text { autonomy and status and they find themselves as salable commodities. They also } \\
\text { suffer from feelings of worthlessness and inferiority. }\end{array}$ \\
\hline Cartwright (2005) & $\begin{array}{l}\text { M\&A is unpredicted and irregular strategic options. It changes the organizational } \\
\text { structure and creates uncertainties that lead to job stress. }\end{array}$ \\
\hline Sajeewani (2012) & $\begin{array}{l}\text { M\&A leads to higher workload, changes in duties, and responsibilities, an increase } \\
\text { in role ambiguity, work overload, and role conflict. }\end{array}$ \\
\hline Joshi and Goyal (2012) & $\begin{array}{l}\text { Ambiguity, timidity, fears concerning job loss, job changes, compensation, } \\
\text { changes in power, status, prestige, workload, working hours, a technological } \\
\text { problem at work, inadequate salary, time for family job worries at home group } \\
\text { differences and communication are the stressors of increasing level of job stress in } \\
\text { M\&A process. }\end{array}$ \\
\hline Joshi and Goyal (2013) & M\&A is the activity that creates job stress among bank employees. \\
\hline Jerjawi (2015) & $\begin{array}{l}\text { M\&A may generate some undesired outcomes such as the loss of jobs due to an } \\
\text { enlarged workforce. }\end{array}$ \\
\hline Giorgi, et al., (2017) & $\begin{array}{l}\text { Stress-related problems such as anxiety and depression are common in the banking } \\
\text { sector. }\end{array}$ \\
\hline $\begin{array}{l}\text { Rodriguez-Sanchez, } \\
\text { Mora-Valentin, } \\
\text { Urbina-Criado (2020) }\end{array}$ & \begin{tabular}{l} 
The focus on HRM aspect supports the success of the M\&A. \\
\hline
\end{tabular} \\
\hline
\end{tabular}

From Table 1, it appears that because of M\&A, mainly, employees of acquired companies feel stress. The International Labour Organization (ILO) also identified that M\&A within the global banking and financial services sector has increased the issues related to human resource management (HRM) such as job insecurity and workplace stress. It is due to the unavoidable likelihood of economizing (ilo.com). Cartwright and Cooper (2005) reported the positive combination of human resources and the fusion of organizational cultures are essential for M\&A practices to be successful. Rodriguez-Sanchez et. al. (2020) also reported that focus on HRM aspect has especial importance in the success of the M\&A practices. Based on these discussions, this study aims to examine the effects of M\&A practices on job stress of employees and to suggest some policies to manage such job stress.

\section{Research Methodology}

This study has followed both descriptive and analytical approaches to research. A set of a self-administered questionnaire has been used to explore the impact of M\&A practice on the job stress of employees. Individualrelated problems, policies and procedures-related problems, job-related problems, and organization-related problems are taken as the key variables that cause to job stress of employees during the period of M\&A practices. The research framework is presented below: 


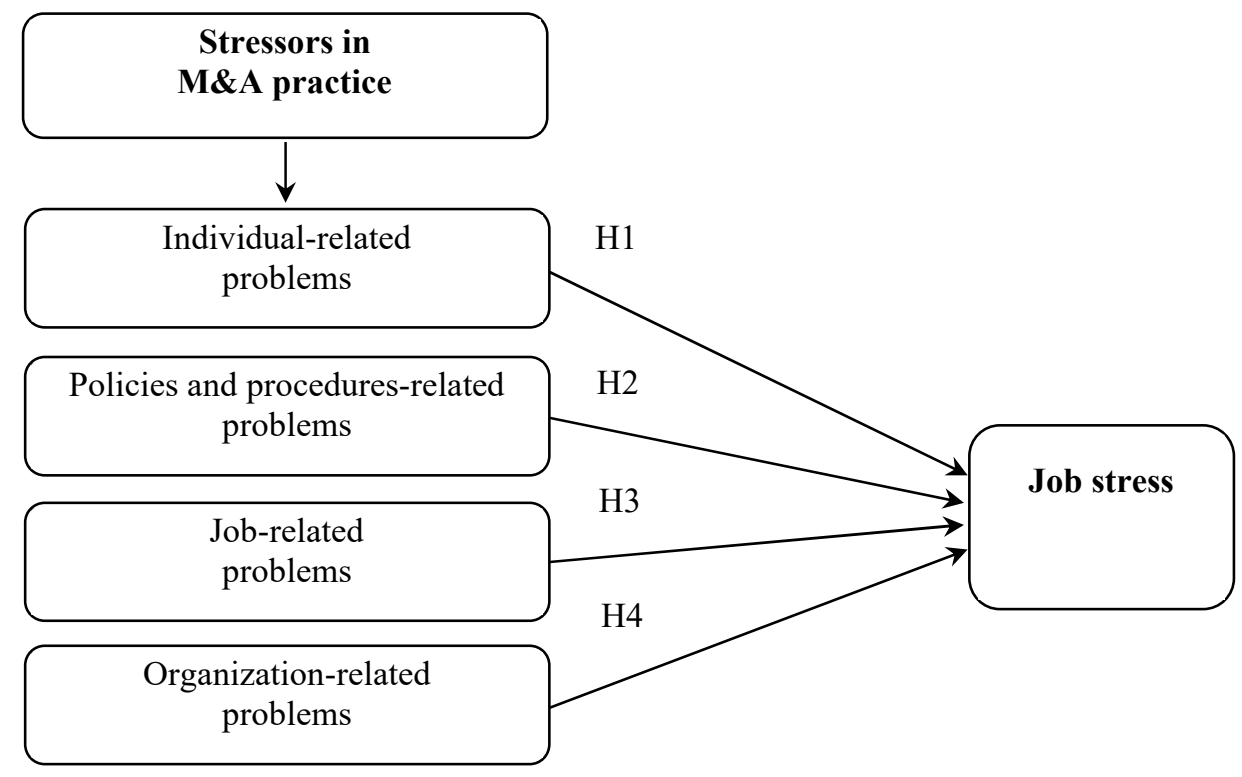

Figure 1. Research Framework

Based on this research framework, the following hypotheses are developed to examine the impact of the stressors in M\&A practice on job stress:

H1: There is a significant impact of individual-related problems occurred due to M\&A practices and job stress of employees

$\mathrm{H} 2$ : There is a significant impact of policies and procedure-related problems that occurred due to M\&A practices and job stress of employees.

H3: There is a significant impact of job-related problems that occurred due to M\&A practices and job stress of employees.

H4: There is a significant impact of organizational-related problems that occurred due to M\&A practices and job stress of employees.

A total of 500 questionnaires (125 in each merged bank) were distributed to all level managers, branch managers, and other staff of various departments of the following selected commercial banks involved in big M\&A practice (see Table 2).

Table 2. Name of Selected BFIs involved in Big M\&A Practices in Nepal

\begin{tabular}{|c|l|c|l|l|}
\hline S.no. & \multicolumn{3}{|c|}{ Name of BFIs } & New name after M\&A practice \\
\hline 1. & Global IME Bank Ltd. & + & Janata Bank Nepal Ltd. & Global IME Bank Ltd. \\
\hline 2. & Bank of Kathmandu Ltd. & + & Lumbini Bank Ltd. & Bank of Kathmandu Ltd. \\
\hline 3. & NIC Bank Ltd. & + & Bank of Asia Ltd. & NIC Asia Bank Ltd. \\
\hline 4. & Prabhu Bank Ltd. & + & Grand Bank Ltd. & Prabhu Bank Ltd. \\
\hline Note: BFIs - Banks and Financial Institutions \\
\hline
\end{tabular}

Only $351(70.20 \%)$ of total distributed questionnaires were returned as a source of data. A five-point Likert scale starting from strongly disagree (1) to strongly agree (5) is used for measuring responses. Data, thus, collected have analyzed using analytical statistical tools such as mean, standard deviation, regression analysis, and ANOVA test.

\section{Results and Discussions}

This section presents the empirical results and findings based on responses of the employees of the selected BIFs that involved in M\&A practices.

\subsection{Descriptive Statistics}

As presented in Table 3, job-related problems are the major stressor that creates job stress among employees after M\&A practice and it is ranked first by the employees. The next stressor is organization-related problems that are followed by policy and procedures-related problems and we can say based on the result that because of many organization-related problems, the employees felt job stress after M\&A and they also faced so many problems related to policies and procedures of M\&A. The stressor that is ranked as fourth is problems related to individual employees themselves. 
Table 3. Descriptive Statistics $(\mathbf{n}=351)$

\begin{tabular}{|c|l|c|c|c|c|}
\hline $\begin{array}{c}\text { S.n } \\
\text { o }\end{array}$ & \multicolumn{1}{|c|}{ Stressors in M\&A practice } & Mean & S.D. & $\begin{array}{c}\text { Reliabilit } \\
\mathbf{y}\end{array}$ & $\begin{array}{c}\text { Ran } \\
\mathbf{k}\end{array}$ \\
\hline 1. & Individual-related problems (Job insecurity) & 3.25 & 0.93 & 0.79 & 4 \\
\hline 2. & $\begin{array}{l}\text { Policies and procedures-related problems } \\
\text { (Unfair practices of performance management and information } \\
\text { security policy) }\end{array}$ & 3.69 & 0.75 & 0.81 & 3 \\
\hline 3. & $\begin{array}{l}\text { Job-related problems } \\
\text { (Lack of necessary information about job position or job } \\
\text { ambiguity) }\end{array}$ & 3.86 & 0.57 & 0.85 & 1 \\
\hline 4. & $\begin{array}{l}\text { Organization-related problems (Difficulty in new corporate } \\
\text { culture, organizational change, information availability issues) }\end{array}$ & 3.75 & 0.79 & 0.83 & 2 \\
\hline Note: All the measures are reliable with a Cronbach's alpha more than 0.70, ranging from 0.79 to 0.85. \\
\hline
\end{tabular}

\subsection{Hypothesis Testing}

This section presents the results of hypothesis testing. The regression model is used for this purpose. The results are presented below:

Table 4. Model Summary of Job Stress and Stressors in M\&A Practice

\begin{tabular}{|c|c|c|c|c|c|}
\hline Model & $\mathrm{R}$ & $\mathrm{R}$ Square & Adjusted R Square & \multicolumn{2}{|c|}{ Std. Error of the Estimate } \\
\hline 1 & 0.926 & $0.857 \mathrm{a}$ & 0.734 & 0.731 & 11.00348 \\
\hline \multicolumn{2}{|l}{ a. Predictors: (Constant), IRP, PPRP, JRP, ORP } \\
\hline
\end{tabular}

Table 5. ANOVA of Job Stress and Stressors

\begin{tabular}{|l|c|c|c|c|c|}
\hline \multicolumn{1}{|c|}{ Sum of Squares } & df & df & Mean Square & F & Sig. \\
\hline Regression & 115736.2 & 4 & 28934.06 & 238.973 & $0.000 \mathrm{a}$ \\
\hline Residual & 41892.51 & 346 & 121.077 & & \\
\hline Total & 157628.7 & 350 & & & \\
\hline a. Predictors: (Constant), IRP, PPRP, JRP, ORP & & \\
b. Dependent variable: Job Stress after M\&A
\end{tabular}

Table 4 expresses the value of R, R2, and adjusted R2 along with standard error of estimate (Se) and Table 5 presents the ANOVA results. Collectively, job stress stressors have explained $85.7 \%$ variance $\left(\mathrm{R}^{2}=0.857, \mathrm{~F}=\right.$ $238.973, \mathrm{p}<0.01)$ in employee job stress. So the model is significant and there is a goodness of fit. It designates that the considered model is statistically accepted.

Table 6. Coefficients of Job Stress

\begin{tabular}{|c|c|c|c|c|c|}
\hline \multirow{2}{*}{ Stressors } & \multicolumn{2}{|c|}{$\begin{array}{c}\text { Standardized } \\
\text { Coefficients }\end{array}$} & \multirow{2}{*}{$\mathbf{t}$} & \multirow{2}{*}{ Sig. } & \multirow[t]{2}{*}{$\begin{array}{l}\text { Supported/ } \\
\text { Rejected }\end{array}$} \\
\hline & B & $\begin{array}{l}\text { Std. } \\
\text { Error }\end{array}$ & & & \\
\hline (Constant) & 49.714 & 4.891 & 10.164 & 0.00 & \\
\hline Individual-Related Problems (IPR) & 0.131 & 0.261 & 0.501 & $0.04 *$ & H1: supported \\
\hline Policies and Procedure-Related Problems (PPPR) & 0.381 & 0.167 & 2.273 & $0.03 *$ & H2: supported \\
\hline Job-related Problems (JPR) & 3.089 & 0.184 & 16.78 & $0.00 * *$ & H3: supported \\
\hline Organization-Related Problems (OPR) & 0.757 & 0.136 & 5.56 & $0.00 * *$ & H4: supported \\
\hline
\end{tabular}

Table 6 provides results regarding the impact of many problems faced by employees after M\&A on job stress. The analyses reveal that individual-related problems have a significantly positive impact on employee job stress $(\beta=0.131, p<0.05)$. Thus, these findings provide support for H1. It shows that when employees have individual problems of job insecurity at their workplaces, then they cause to increase job stress. As there is a significantly positive impact between them, a unit of job insecurity increases its magnitude effect on job stress also soars up by the 0.131 unit. This might happen because after M\&A practice, every employee should be more competitive within the merged (i.e. large) company to perform better in the market which ultimately trickles down to the employees. They should correct their problems so that they can feel safe in the new company. Thus, M\&A practice might have lead to increased job stress of the employees in the new company.

The results show that policies and procedure-related problems have a significant positive relationship with job stress $(\beta=0.381, \mathrm{p}<0.05)$. This finding provides support for $\mathrm{H} 2$. It shows that if employees feel unfair practices of performance management systems and information security policies in a new company, at that moment, they 
cause to increase their job stress. As there is a significantly positive relationship between them, a unit of performance management issues increases its magnitude effect on job stress rises by the 0.381 unit. This might take place because after M\&A practices every new company needs to change and reform employee compensation guidelines and performance management policies to manage human resources cost-effectively. This leads to major changes in policies and procedures-related change in the new company directly concerning employees and leads to an increase in their job stress level.

The results report that job-related problems also have a significant positive impact on employee job stress $(\beta$ $=3.089, \mathrm{p}<0.01)$. This finding provides support for H3. It shows that if the employees suffer from the lack of necessary information about the organizational position in the new company, then, it causes them to increase their job stress. As there is a significantly positive relationship between them, a unit increases in job ambiguity has a magnitude effect on job stress up by the 3.089 unit. This might happen because after M\&A practice employees face changes in their corresponding roles and responsibilities and if there lacks an effective flow of necessary information about their job positions and job assignments, it increases their job stress in the new company.

The findings also presents that issues related to the organization have a substantial positive relationship with job stress $(\beta=0.757, p<0.01)$. Thus, this finding provides support for H4. This presents the fact that if the employees feel difficulty adapting to new corporate culture, organizational change, and an issue of knowledge availability in the new company, then it causes them to increase their job stress. As there is a substantially positive relationship between them, the 0.757 unit has a magnitude impact on job stress due to a unit increase in organization-related problems. This may be because the new business would be established with the new corporate culture after the M\&A process. Organizational changes in terms of organizational hierarchy and structure will take place. Likewise, a flow of information in terms of new communication systems may change affecting employees' work-life in terms of change in the workplace, job position, working groups, and channel of information and its availability. This leads to major changes in employees' lifestyles, habits, and work behavior enhancing job stress levels in the new company.

\section{Conclusions and Implications}

It is commonly believed that M\&A is a kind of transitional phase for organizational life. Due to such a transitional phase, there can be some changes in organizational culture, policies, and practices that create a kind of uncertainty regarding the job and job-related matters. Such uncertainly creates job stress for employees in the new company after M\&A. Obviously, M\&A has been offering several benefits to today's companies making them competitive enough in such a competitive world (Basnet \& Acharya, 2018). It is increasingly more getting used by companies to reinforce and hold their position in the marketplace (Schuler \& Jackson, 2001) but it has also been creating a sense of fear and insecurity in the minds of employees that ultimately create job stress. Previous studies report that the success rates of M\&A are low. In one study, Kafle (2012) found that the success rate of M\&A is 15 percent in the last seven years. Such failure of M\&A could be caused by the presence of employees' job stress and fall in overall organizational performance.

The study also discloses that, among the stressors, job-related problems are ranked first which is followed by organization-related problems and policy and procedures-related problems. Individual-related problems are ranked at least. However, these all problems are responsible to create job stress among employees of the new company. As per the results of this study, we can conclude that M\&A practice creates individual-related problems of employees. There is also the risk of dispute or conflict between the combining or purchasing company employees and the principal company.

The new company could adjust performance management systems and guidelines after M\&A experience and also create job stress in the minds of the merged or acquired company's employees. They feel unsecured and uncertain about their future for this reason. These results tend to be consistent with Seo and Hill (2005); Saneewani (2012), and Basnet and Acharya (2018).

Further, we can conclude that the practice of M\&A also creates many problems related to policies and procedures, job, and organization. Mainly, unfair practices of performance management and information security policy, lack of necessary information about job position or job ambiguity, and difficulty in new corporate culture, organizational change, information availability issues create job stress to the employees in the new company. In fact, due to M\&A practice, the employees may have several psychological problems including uncertainty, job insecurity, job changes, and the threat of job loss that create job stress. At the same moment, change in working culture, technology, work assignments, working hours, communication systems, relationship with new company staff and seniors, newness in supervision, information unavailability, and unlearned work behavior and new organizational structure also contribute to enhancing job stress after M\&A practice.

Based on these discussions, we suggest the following policy implications for managing and reducing the job stress of employees after M\&A practices have taken place:

- Job stress if not handled efficiently results in a negative effect on employee morale (Srivastava, 2016). So, to reduce such stress it is necessary to develop a clear vision and business approach of the M\&A during 
the period of cooperation, and feature it prepared for information flow throughout the two companies (Vijaywargia, 2016).

- It is also required to develop a replacement chart, and take up an intensive audit of the abilities of the team of workers to map their roles and responsibilities as aligned with the brand new chart.

- An establishment of a strong communication system also would be helpful to reduce the fears and anxiety amongst the employees of the merged or acquired companies.

- $\quad$ Easy accessibility of employees to the senior management teams to express their views and opinions also helps to minimize employee job stress.

- Employee participation in productive work and keeping their motivation and commitment high would be better to reduce employee job stress.

- Unmanaged cultural differences can result in miscommunications and misunderstandings that cause job stress among the workers. So, employee communications, retention of key employees, and cultural integration are the most important activities in the HR area for successful M\&A integration (Bobier, 2000, cited in Horwitz and Budhwar, 2015). These all would be helpful to minimize employees' job stress that arises due to the M\&A practice.

\section{References}

Adeyinka, J.A., Emanuel, I.O., \& Daniel, A.A. (2015). Mergers and acquisition: The solution to the problem of ineffective financial intermediation in the Nigerian banking system. Journal of Research in Business, Economics and Management, 4(4), 1-14.

Ashford, S. J., Lee, C., \& Bobko, P. (1989). Content, causes, and consequences of job insecurity: A theory-based measure and substantive test. Academy of Management Journal, 32(4), 803-829.

Bartels, J., Douwes, R., Jong, M.D., \& Pruyan, A. (2006). Organizational identification during a merger: Determinants of employees' expected identification with the new organization. British Journal of Management, 17(3), 49-67.

Basnet, R., \& Acharya, S. (2018). Effects of merger and acquisition on employees' job stress: study of commercial banks of Nepal. Journal of Business and Economics Research, 2(3), 5-18.

Bobier, S. (2000). Personal communication in a company seminar for J\&J, November 7.

Buone, A.F., \& Bowditch, J.L. (1989). The human side of mergers and acquisitions: Managing collisions between people, cultures, and organizations. San Francisco: Jossey-Bass.

Cartwright, S. (2005). Merger and acquisition: An update and appraisal. Hodgkinson, G.P. and Ford, J.K. (Eds.). International Review of Industrial and Organizational Psychology, 20, Wiley, Chicester, 1-38.

Cartwright, S., \& Cooper, C.L. (2005). The impact of mergers and acquisitions on people at work. British Journal of Management, 1(2), 65 - 76.

Cartwright, S., \& Cooper, C.L. (2014). Mergers and acquisitions: The human factor. United Kingdom: Butterworth-Heinemann.

David, F.R. (2011). Strategic management: concepts and cases. One Lake Street, Upper Saddle River, New Jersey: Pearson Education, Inc.

Dhungana, S. (2013, 6, 24). Nepali banking in transition through mergers and IPOs. New Business Age, p.1.

Geber, B. (1987, February). The forgotten factor in merger mania. Training Magazine, 28-37.

Gibbons, C. (1998). An investigation into the effects of organizational change on occupational stress in further education lecturers. Journal of Further and Higher Education, 22(3), 315-317.

Giogi, G., Arcangeli, G., Perminience, M., Lorini, C., Ariza-Montes, A., Fiz-Perez, J, Di Fabio, A., \& Mucci, N. (2017). Work-related stress in the banking sector: A Review of Incidence, Correlated Factors, and Major Consequences. Frontiers in Psychology 12(8), DOI: 10.3389/fpsyg.2017.02166.

Goyal, K.A., \& Joshi, V. (2014). Impact of merger on stress level of employee (A case study of Erstwhile Bank of Rajasthan Limited). International Journal of Business Research and Management, 3(5), 1-15.

Habeck, M. M., Kroger, F., \& Trâm, M. R. (2000). After the merger: Seven rules for successful post-merger integration. Great Britain: Pearson Education Limited.

Horwitz, F., \& Budhwar, P. (2015). handbook of human resource management in emerging markets. UK: Edward Elgar Publishing Limited.

Hubbard, G., Rice, J., \& Galving, P. (2015). Strategic management: thinking, analysis, action. Melbourne: Pearson Australia.

Jerjawi, K.A. (2015). The role of human resource executives in mergers: a comparative case study of two bank mergers-the merger of Westpac Corporation and St. George Bank (Australia) and The Merger of Emirates Bank International and the National Bank of Dubai (UAE). School of Business University of Western Sydney, Sydney.

Joshi, V., \& Goyal, K. A. (2012). Stress management among bank employees: with reference to mergers and acquisitions. International Journal of Business and Commerce, 1(5), 22-31. 
Joshi, V., \& Goyal, K. A. (2013). Post-merger appraisal of stress level among bank employees: a case study. Journal of Social and Development Sciences, 4(4), 152-163.

Kafle, B.C. (2012, October 5). Mergers and acquisition in Nepalese banking sector. BOSS, 1-3.

Kahn, R.L., Wolfe, D.M., Quinn, R.P., Snoek, J.D. \& Rosenthal, R.A. (1964). Organizational stress: studies in role conflict and ambiguity. John Wiley, 455-461.

Machiraju, H. (2003). Mergers, acquisitions and takeovers. New Delhi: New Age International (P) Ltd.

Matteson, M.T., \& Ivanceich, J.M. (2008). Merger and Acquisition Stress: Fear and Uncertainty at Mid-Career. Prevention in Human Services, 8(1), 139-158.

Moran, P., \& Panasian, C. (2005). The human side of mergers and acquisitions: A look at the evidence. Maule: Universidad De Talca.

Nepal Rastra Bank (NRB) (2015). Unified directives issued by Nepal Rastra Bank to the licensed banks and financial institutes. Kathmandu: Nepal Rastra Bank.

Panthi, S. (2012). Major reasons for Nepalese finance companies' merger failure-Case-Synergy Finance Ltd. Helsinki: Arcada University.

Rao, P. S. (2016). Business policy and strategic management: text and cases. Mumbai: Himalaya Publishing House.

Roberts, P.A., Wallace, D.W., \& Moles, D.P. (2010). Mergers and acquisitions. Edinburgh, Scotland: Heriot-Watt University.

Rodriguez-Sanchez, J., Mora-Valentin, E.M., \& Urbina-Criado, M.O. (2020). Human resource management in merger and acquisition planning. Journal of Organizational Change Management 33(1), 16-28.

Sajeewani, R.N. (2012). The impact of company acquisition on employees' job stress: A study on a telecommunication firm in Sri Lanka. Moratuwa: Department of Management of Technology.

Schuler, R., \& Jackson, S. (2001). HR issues and activities in mergers and acquisitions. European Management Journal 19(3), 239-253.

Schweiger, D.M. \& Ivancevich, J. (1987, November). Human resources: The forgotten factor in mergers and acquisitions. Personnel Administrator, 47-61.

Seo, M.G., and Hill, N.D. (2005). Understanding the human side of merger and acquisition. The Journal of Applied Behavioural Science, 41(4), 422-443.

Shrestha, P. (2019). Effect of merger and acquisition practice in financial institutions of Nepal. Journal of Balkumari College, 8, 5-9.

Srivastava, A. (2016). Impact of mergers \& acquisitions on employee's effectiveness. International Journal of Commerce and Management Research, 2(9), 119-121.

Thompson, J. and Martin, F. (2005). Strategic management: awareness and change. U.K: Cengage Learning EMEA.

Vijaywargia, T. (2016). Analyzing the consequences of mergers and acquisitions on human resource. Global Journal of Commerce \& Management Perspective, 5(1), pp. 32-34.

Wheelen, T.L, Hunger, J.D., Hoffman, A.N., \& Bamford, C.E. (2018). Strategic management and business policy: globalization, innovation and sustainability. UK: Pearson Education Limited.

Whittle, D.D. (2002). Mergers and acquisitions: the employee perspective. Iowa State University, USA. 